\title{
CARACTERÍSTICAS DE CULTURAS LÁCTICAS PROBIÓTICAS PARA USO EM PRODUTOS CÁRNEOS FERMENTADOS: SENSIBILIDADE AOS SAIS DE CURA E USO DE ANTIBIÓTICOS PARA CONTAGEM SELETIVA
}

\author{
RENATA E. FREITAS DE MACEDO * \\ SÉRGIO BERTELLI PLANZER JR ** \\ NELCINDO NASCIMENTO TERRA *** \\ RENATO J. SOSSELA FREITAS ****
}

\begin{abstract}
Os objetivos deste trabalho foram avaliar a resistência de espécies probióticas de Lactobacillus na presença de sais de cura e testar sua sensibilidade frente a diferentes antimicrobianos para o desenvolvimento de meio de cultura seletivo. As culturas Lactobacillus casei, Lactobacillus paracasei e Lactobacillus rhamnosus foram semeadas em ágar MRS contendo concentrações de $0 \%$ a $3 \%$ de cloreto de sódio e 0 a 200 ppm de nitrito de sódio. O efeito do uso concomitante dos sais de cura foi verificado utilizando-se $3 \%$ de cloreto de sódio e 200 ppm de nitrito de sódio. As bactérias probióticas e a cultura starter Pediococcus pentosaceus foram testadas frente a 20 discos de antimicrobianos pela técnica de disco-difusão. $O$ crescimento dos probióticos não apresentou alteração nas diferentes concentrações de cloreto de sódio, assim como nas concentrações de até 200 ppm de nitrito de sódio. Verificou-se resistência ao uso simultâneo de cloreto e nitrito de sódio. Entre os antimicrobianos testados, a tetraciclina apresentou resultados satisfatórios para a inibição dos probióticos permitindo o crescimento isolado da cultura starter. Os probióticos apresentaram desenvolvimento satisfatório na presença dos sais de cura, demonstrando potencial para sua utilização em produtos cárneos fermentados com ação probiótica.
\end{abstract}

PALAVRAS-CHAVE: PROBIÓTICOS; PRODUTO CÁRNEO FERMENTADO; SAIS DE CURA.

\footnotetext{
* $\quad$ Curso de Medicina Veterinária, Pontifícia Universidade Católica do Paraná, (PUCPR), Programa de Pós-Graduação em Tecnologia de Alimentos, (UFPR) Curitiba, PR (e-mail: renata.macedo@pucpr.br).

** Graduando do Curso de Medicina Veterinária, PUCPR.

*** Universidade Federal de Santa Maria (UFSM) e Programa de Pós-Graduação em Tecnologia de Alimentos, UFPR.

**** Programa de Pós-Graduação em Tecnologia de Alimentos, UFPR.
} 


\section{INTRODUÇÃO}

Devido às suas propriedades terapêuticas e de manutenção do equilíbrio da microbiota intestinal, as bactérias lácticas probióticas têm sido muito utilizadas como agentes funcionais em alimentos, principalmente em produtos lácteos (LÜCKE, 2000). Culturas probióticas com ação funcional são, por definição, aquelas que após ingestão em número suficiente exercem efeitos benéficos à saúde, além de seu efeito nutricional (HAMMES e HERTEL, 1998; LÜCKE, 2000).

Dentre os derivados cárneos em que o uso de bactérias probióticas seria benéfico, os produtos fermentados como o salame são os que apresentam as melhores perspectivas. Esses são fabricados com carne crua e consumidos sem prévio aquecimento, o que causaria a morte dos microrganismos (ERKKILÄ et al., 2001).

Um dos grandes desafios na produção de produtos cárneos fermentados com culturas probióticas está em sua sensibilidade ao sal e aos agentes de cura utilizados como ingredientes. Nesse sentido, a seleção de culturas probióticas capazes de crescer na presença de sais de cura seria o primeiro passo para a elaboração de alimentos fermentados com características funcionais (SAMESHIMA et al., 1998; ANDERSEN, 1998).

Entende-se por cura da carne a adição de sal (cloreto de sódio), nitrato e/ ou nitrito e demais ingredientes necessários para conferir características únicas de sabor, aroma e coloração ao produto (CANHOS e DIAS, 1985). O sal é o principal agente de cura. Atua como conservante pela diminuição da atividade de água do produto, desidratação das bactérias e ação tóxica do íon cloro. É também agente flavorizante (valores iniciais de $2,5 \%$ a $3 \%$ ), contribuindo para o sabor típico do produto curado (CANHOS e DIAS, 1985; TYÖPPÖNEN, PETÄJÄ e MATTILASANDHOLM, 2003).

Os nitratos e/ ou nitritos são utilizados como ingredientes obrigatórios no processo de cura dos produtos cárneos. A adição desses sais à matéria-prima objetiva a formação de coloração avermelhada (mediante cadeia de reações com a mioglobina), a inibição do crescimento de microrganismos patogênicos (principalmente Clostridium botulinum), a proteção contra oxidação lipídica e a formação de sabor e aroma típicos no produto (CANHOS e DIAS, 1985; TYÖPPÖNEN, PETÄJÄ e MATTILASANDHOLM, 2003). Por serem considerados obstáculos ao crescimento 
de microrganismos indesejáveis, proporcionando segurança microbiológica aos produtos cárneos, os sais de cura também podem inibir as culturas probióticas adicionadas ao produto. Dessa forma, o emprego de bactérias probióticas resistentes ao nitrito, ao nitrato e ao cloreto de sódio é a primeira condição para a produção de derivados cárneos fermentados com ação probiótica (PAMANOLI et al., 2003).

$\mathrm{Na}$ formulação de produtos cárneos fermentados empregam-se, tradicionalmente, bactérias lácticas denominadas de culturas starter. Essas culturas são utilizadas visando garantir a segurança microbiológica do produto, aumentar a estabilidade mediante a inibição do crescimento de microrganismos indesejáveis e melhorar as características sensoriais (LÜCKE, 2000). Entre as bactérias lácticas que podem ser utilizadas como starter inclui-se o Pediococcus pentosaceus, que por pertencer ao mesmo grupo de bactérias lácticas dos Lactobacillus deve ter sua contagem nos produtos cárneos diferenciada da contagem de lactobacilos probióticos. Em virtude da utilização de mais de uma espécie de bactéria láctica em alimentos probióticos torna-se necessário o uso de métodos de contagem seletiva para os microrganismos presentes no alimento. Estudos que visam o desenvolvimento de novos métodos para contagem seletiva de bactérias probióticas baseiam-se, principalmente, na utilização de diferentes temperaturas de incubação e adição de carboidratos e/ou antibióticos ao meio de cultura (THARMARAJ e SHAH, 2003).

Os objetivos do presente trabalho foram avaliar a resistência de espécies probióticas de Lactobacillus na presença de sais de cura e testar sua sensibilidade a diferentes antimicrobianos para o desenvolvimento de meio de cultura seletivo.

\section{MATERIAL E MÉTODOS}

\subsection{MATERIAL}

As culturas lácticas probióticas utilizadas foram cepas de Lactobacillus das seguintes espécies:

- Lactobacillus casei (LC 01 CHR HANSEN), obtida sob a forma liofilizada e fornecida pela empresa LC Bolonha,

- Lactobacillus paracasei ssp paracasei (ATCC 10746/ CCT 0566),

- Lactobacillus casei ssp rhamnosus (ATCC 7469/ CCT 6645). Essas últimas foram obtidas sob a forma reativada em ágar de Man, Rogosa e Sharpe (MRS) da Coleção de Culturas Tropicais da Fundação André Tosello. 


\subsubsection{Teste de sensibilidade das culturas lácticas aos sais de cura}

As cepas foram testadas quanto à resistência ao cloreto de sódio adicionado ao ágar MRS (CARR, CHILL e MAIDA, 2002) nas concentrações de $1 \%, 1,5 \%, 2 \%, 2,5 \%$ e $3 \%$. Os testes de resistência ao nitrito e ao nitrato foram realizados pelo mesmo procedimento utilizando concentrações de 80, 100, 120, 150 e 200 ppm adicionadas ao ágar MRS (ARIHARA e ITOH, 2000).

As culturas lácticas foram primeiramente repicadas em tubos de ensaio contendo, aproximadamente, $10 \mathrm{~mL}$ de caldo MRS e incubadas a $37^{\circ} \mathrm{C}$ por 24 horas para reativação de sua viabilidade. Após reativação procedeuse a diluição dos inóculos em água peptonada $0,1 \%$ até a concentração $10^{-7}$. Posteriormente semeou-se $1 \mathrm{~mL}$ dessa concentração em placas de Petri contendo ágar MRS, adicionado das diferentes concentrações de sais de cura. Paralelamente, também foram semeadas alíquotas de $1 \mathrm{~mL}$ dos inóculos em ágar MRS puro (teste controle) para comparação do crescimento das culturas. Utilizou-se a técnica de semeadura em profundidade (pour plate) visto que as bactérias lácticas são microrganismos microaerófilos. A incubação das placas ocorreu em estufa bacteriológica a $37^{\circ} \mathrm{C}$, durante 48 horas. A avaliação do crescimento das culturas probióticas foi realizada pela contagem das colônias presentes nos meios de cultura com diferentes concentrações de sais de cura, sendo os resultados (expressos em UFC/ $\mathrm{mL}$ ) comparados com o teste controle (SILVA, JUNQUEIRA e SILVEIRA, 2001).

\subsubsection{Teste de sensibilidade das culturas lácticas aos antimicrobianos}

As bactérias lácticas da cultura startere as bactérias lácticas probióticas foram testadas frente a 20 antimicrobianos pelo método de disco-difusão. Partindo-se de $10 \mathrm{~mL}$ de caldo MRS com as culturas pré-ativadas por 24 horas a $37^{\circ} \mathrm{C}$ foram realizados esfregaços utilizando swab em ágar MRS. Após a secagem do esfregaço no ágar foram depositados sobre sua superfície dez discos de antimicrobianos (LABORCLIN), utilizando-se duas placas para cada microrganismo. As placas foram incubadas em estufa bacteriológica por 24 horas a $37^{\circ} \mathrm{C}$ e a sensibilidade aos microbianos verificada pelo diâmetro (em milímetros) dos halos de inibição formados ao redor do disco (LABORCLIN, 2003). 
A confirmação do crescimento seletivo dos pediococos na presença de tetraciclina ocorreu pela contagem de cepas puras de Pediococcus pentosaceus, Lactobacillus casei, L. paracasei spp paracaseie L. casei spp rhamnosus em ágar MRS com a adição de $10 \mathrm{mg} / \mathrm{L}$ de tetraciclina e sem a adição do antibiótico. A partir da solução de $0,05 \mathrm{~g}$ de tetraciclina (SIGMA Chemical Co.) por $100 \mathrm{~mL}$ de água destilada foram adicionados $20 \mathrm{~mL}$ da solução em $1000 \mathrm{~mL}$ de ágar MRS, obtendo-se a concentração desejada de antibiótico no meio de cultura. As culturas puras foram diluídas em água peptonada estéril $0,1 \%$ e o plaqueamento das diluições $10^{-2} \mathrm{a}$ $10^{-9}$ realizado pela técnica pour plate. As placas inoculadas em duplicata com e sem a adição do antibiótico foram incubadas a $37^{\circ} \mathrm{C}$ por 48 horas para a contagem do número de colônias (THARMARAJ e SHAH, 2003).

\section{RESULTADOS E DISCUSSÃO}

\subsection{CRESCIMENTO DAS BACTÉRIAS LÁCTICAS PROBIÓTICAS SOB DIFERENTES CONCENTRAÇÕES DE SAIS DE CURA}

O desenvolvimento de probióticos para produtos cárneos fermentados pressupõe o uso de bactérias probióticas resistentes ao nitrito e ao cloreto de sódio, capazes de crescer rapidamente durante a fermentação. Também devem apresentar resistência à acidez, à lisozima e à bile, mostrando capacidade para colonizar o trato intestinal humano mediante mecanismos de aderência ou ligação às células intestinais (PAPAMANOLI et al., 2003).

O número de células viáveis dos lactobacilos testados nas diferentes concentrações de cloreto de sódio está apresentado na Figura 1.

Nas contagens realizadas em ágar MRS com adição de $1 \%$ a $3 \%$ de cloreto de sódio, todas as culturas de Lactobacillus testadas apresentaram elevado número de células viáveis quando comparadas ao controle (sem adição de cloreto de sódio). Para as três espécies de Lactobacillus avaliadas houve ligeiro aumento no número de células viáveis com maior adição de cloreto de sódio ao meio de cultura, exceto para L. rhamnosus na concentração de $3 \%$ de sal. Os lactobacilos apresentaram resistência aos níveis de cloreto de sódio testados, mostrando possibilidade de sua utilização em produtos cárneos fermentados para os quais é recomendada a adição de $3 \%$ de $\mathrm{NaCl}$ no intuito de assegurar proteção contra microrganismos indesejáveis (SAMESHIMA et al., 1998). 


\section{FIGURA 1 - CRESCIMENTO DAS CEPAS DE LACTOBACILOS TESTADOS SOB DIFERENTES CONCENTRAÇÕES DE CLORETO DE SÓDIO (NaCl)}

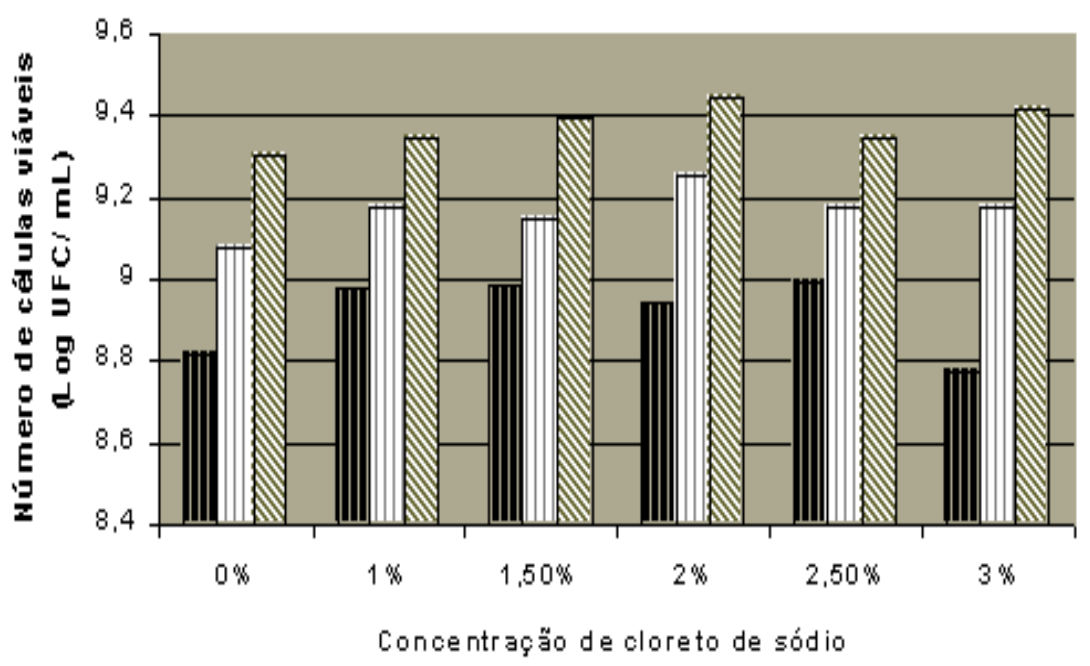

口L. rham nosus qL.paracasei $\mathbb{Q}^{L}$. casei

A adição de nitrito de sódio ao meio de cultura até a concentração de 200 ppm também se mostrou suportável pelas culturas probióticas testadas, não afetando seu crescimento em relação ao meio de cultura puro (Figura 2). As bactérias apresentaram adequada viabilidade nos meios testados, atingindo concentrações celulares de $7,0 \mathrm{x}$ $10^{8} \mathrm{UFC} / \mathrm{mL}, 1,7 \times 10^{9} \mathrm{UFC} / \mathrm{mL}$ e $3,1 \times 10^{9} \mathrm{UFC} / \mathrm{mL}$ para L. rhamosus, $L$. paracasei e $L$. casei, respectivamente. Alega-se que os alimentos com propriedade probiótica devam conter número mínimo de células viáveis de bactérias lácticas de $10^{6}$ Unidades Formadoras de Colônia por grama para a obtenção de efeitos benéficos e colonização do intestino (LÜCKE, 2000; FERREIRA, 2003; THARMARAJ e SHAH, 2003). Os Lactobacillus testados mostraram número de células viáveis superior ao recomendado para obtenção do efeito probiótico na presença de sais de cura.

A Figura 2 mostra o crescimento das espécies de Lactobacillus $s p$ testadas nas diferentes concentrações de nitrito de sódio. 
FIGURA 2 - CRESCIMENTO DAS CEPAS DE LACTOBACILOS TESTADOS EM ÁGAR MRS SUPLEMENTADO COM DIFERENTES CONCENTRAÇÕES DE NITRITO DE SÓDIO $\left(\mathrm{NaNO}_{2}\right)$

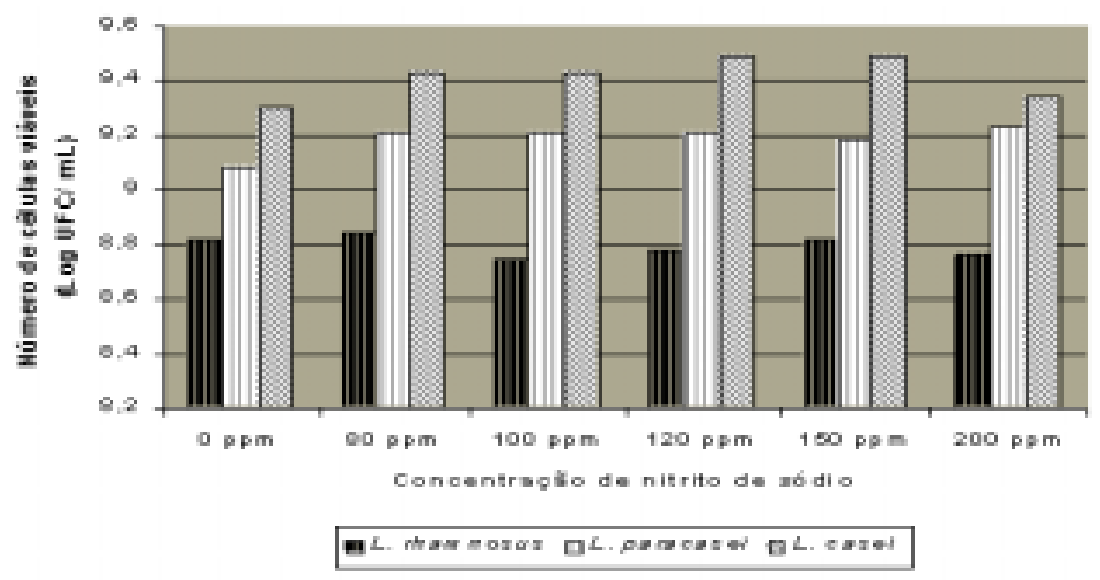

O número de células viáveis das bactérias lácticas, obtido com o uso concomitante de cloreto de sódio e nitrito de sódio está apresentado na Figura 3.

FIGURA 3 - CRESCIMENTO DAS CEPAS DE LACTOBACILOS TESTADAS EM MEIO SUPLEMENTADO COM $3 \%$ DE CLORETO DE SÓDIO (NaCl) E 200 ppm DE NITRITO DE SÓDIO $\left(\mathrm{NaNO}_{2}\right)$

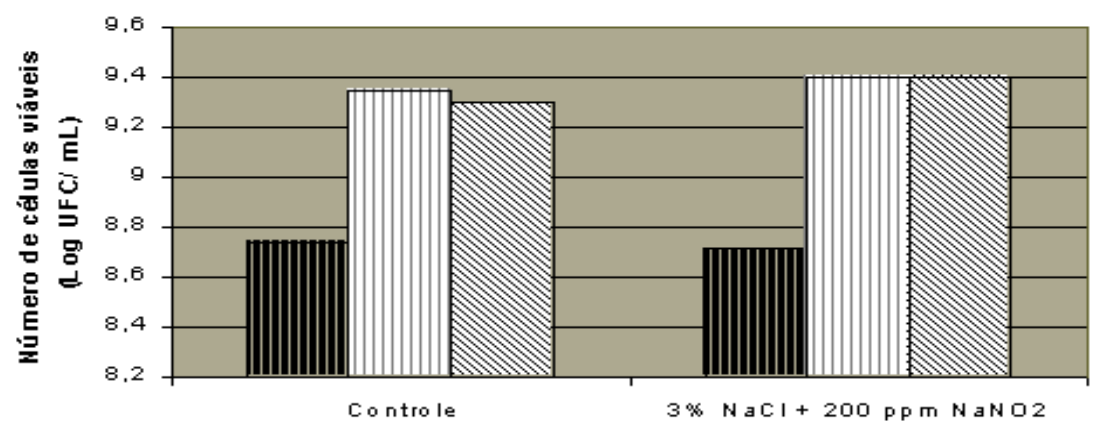

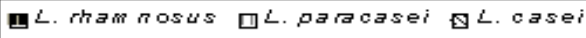


Segundo ARIHARA e ITOH (2000), os produtos cárneos no Japão devem receber a adição de $3 \%$ de cloreto de sódio e 200 ppm de nitrito de sódio para a manutenção da segurança microbiológica. Dessa forma, as bactérias probióticas usadas nesses produtos devem ser capazes de resistir ao uso concomitante das referidas concentrações de sais de cura. As espécies de Lactobacillus utilizadas neste trabalho mostraram adequada resistência ao uso simultâneo de cloreto e de nitrito de sódio nas concentrações de $3 \%$ e 200 ppm, respectivamente.

SAMESHIMA et al. (1998) testaram a resistência de 202 espécies de lactobacilos de origem intestinal frente ao nitrito de sódio e ao cloreto de sódio, adicionados em meio líquido. Observaram que as cepas de $L$. paracasei ssp paracasei, L. rhamnosus e L. acidophilus mostraram-se tolerantes a esses sais.

\subsection{SENSIBILIDADE DAS BACTÉRIAS LÁCTICAS FRENTE AOS DIFERENTES ANTIMICROBIANOS}

Sabendo-se que o efeito probiótico somente é promovido pela ingestão de células viáveis de bactérias benéficas, a contagem diferenciada desses microrganismos mediante método de enumeração seletiva constitui importante parâmetro para o monitoramento de sua viabilidade nos alimentos. O teste de suscetibilidade microbiana aos antibióticos pode ser utilizado como ferramenta para o desenvolvimento de meios de culturas seletivos (CARR, CHILL e MAIDA, 2002; THARMARAJ e SHAH, 2003).

Entre os antimicrobianos testados, somente três evidenciaram grau de ação inibitória diferenciada para as bactérias lácticas utilizadas. A rifampicina inibiu o crescimento de todas as cepas testadas com exceção do Lactobacillus casei que mostrou-se resistente. Todas as cepas testadas evidenciaram resistência à vancomicina conforme estudos descritos por ERKKILÄ et al. (2001). Resultados semelhantes foram obtidos por THARMARAJ e SHAH (2003) em ágar MRS adicionado de $1 \mathrm{mg} / L$ de vancomicina, no qual $L$. casei e $L$. rhamnosus apresentaram crescimento. De acordo com CARR, CHILL e MAIDA (2002) as bactérias lácticas dos gêneros Pediococcus, Leuconostoc, Lactococcus e alguns Lactobacillus mostram-se resistentes à vancomicina na concentração de $30 \mu \mathrm{g}$ em teste de disco-difusão Por sua vez, a ampicilina e a tetraciclina evidenciaram eficiência na inibição das cepas de Lactobacillus, enquanto o pediococo apresentou-se resistente à ampicilina e pouco sensível à tetraciclina (Tabela 1). 


\section{TABELA 1 - RESULTADOS OBTIDOS NO TESTE DE SUSCETIBILIDADE DAS CULTURAS LÁCTICAS AOS ANTIMICROBIANOS PELO MÉTODO DE DISCO-DIFUSÃO}

\begin{tabular}{|c|c|c|c|c|c|c|}
\hline \multirow[t]{2}{*}{ Antimicrobianos } & \multicolumn{2}{|c|}{$\begin{array}{c}\text { Padrão irterpretativo } \\
\text { (zonas de inibiçä0 em mm) * }\end{array}$} & \multicolumn{4}{|c|}{ Zonas de inibição utilizando bactérias lácticas (mm) } \\
\hline & Resistente & $\begin{array}{l}\text { lyadutimi। } \\
\text { Suscetivel }\end{array}$ & Aediacocces & L. casei & L. mamnosus & L. paracasei \\
\hline $\begin{array}{l}\text { Anoxidinatádido } \\
\text { dạulậnion }\end{array}$ & $\measuredangle 19$ & 20 & 24 & 24 & 25 & 23 \\
\hline Ampicilina & $\measuredangle 19$ & 20 & 19 & 25 & 26 & 22 \\
\hline Bacitracina & $<08$ & 213 & 4 & 7 & 6 & 0 \\
\hline Cefalexina & $\$ 14$ & 218 & 23 & 20 & 22 & 18 \\
\hline Cefalotina & \4 & 218 & 23 & 24 & 24 & 22 \\
\hline Ciprofloxadina & $\measuredangle 15$ & $>21$ & 2 & 11 & 16 & 6 \\
\hline Clorafeniool & $\measuredangle 12$ & $>18$ & 24 & 26 & 24 & 22 \\
\hline Eritromicina & 43 & $\$ 18$ & 22 & 28 & 26 & 31 \\
\hline Estreptomidina & $\$ 11$ & 215 & 2 & 8 & 2 & 10 \\
\hline Gentanidina & $\measuredangle 12$ & $>15$ & 8 & 10 & 10 & 8 \\
\hline Imipenem & $\measuredangle 13$ & $\$ 16$ & 27 & 24 & 28 & 24 \\
\hline Kanamicina & $८ 13$ & $\$ 18$ & 2 & 9 & 0 & 0 \\
\hline Neomicina & $\measuredangle 12$ & $\$ 17$ & 11 & 12 & 8 & 11 \\
\hline Norfloxadina & $\measuredangle 12$ & $\$ 17$ & 2 & 8 & 10 & 12 \\
\hline Oxacilina & $<09$ & $\$ 14$ & 2 & 10 & 10 & 0 \\
\hline Penicilina G. & $<0$ & 229 & 23 & 25 & 28 & 25 \\
\hline Rifannidira & ८4 & $>25$ & 25 & 24 & 28 & 28 \\
\hline Sulforan ida & $\measuredangle 12$ & 217 & 2 & 6 & 0 & 5 \\
\hline Tetradidina & $\$ 14$ & $>19$ & 16 & 30 & 26 & 28 \\
\hline Vancomidina & $<09$ & $\$ 12$ & 2 & 2 & 0 & 0 \\
\hline
\end{tabular}

* LABORCLIN, 2003.

CARR, CHILL e MAIDA (2002) afirmaram que a adição de $5 \mathrm{mg} / \mathrm{L}$ de ampicilina ao ágar MRS permite o crescimento seletivo de Pediocccus pentosaceus. Verificou-se que a enumeração isolada de Pediococcus poderia ser realizada com a adição de tetraciclina ou ampicilina ao meio de cultura. Devido ao menor custo e maior facilidade para obtenção de tetraciclina no mercado brasileiro, esse antimicrobiano foi selecionado para as contagens diferenciais das bactérias lácticas utilizando-se a concentração de $10 \mathrm{mg}$ de tetraciclina/L de meio de cultura.

O número de células viáveis de Pediococcus e de Lactobacillus em ágar MRS com e sem a adição de tetraciclina estão apresentados na 
Tabela 2.

TABELA 2 - CONTAGEM DE PEDIOCOCCUSE LACTOBACILLUSEM MEIO DE CULTURA COM E SEM A ADIÇÃO DE TETRACICLINA (10 mg/L)

\begin{tabular}{|c|c|c|c|c|}
\hline $\begin{array}{c}\text { Meio de cultura } \\
\text { Ágar MRS }\end{array}$ & $\begin{array}{l}\text { Pediococaus } \\
\text { pentosaceus }\end{array}$ & L. casej & L. paracasej & L. mamnosus \\
\hline Sem adiçẩo de tetraciclina & $2,50 \times 10^{8}$ & $1,48 \times 10^{9}$ & $1,43 \times 10^{9}$ & $9,35 \times 10^{8}$ \\
\hline $\begin{array}{l}\text { Com adiç̧ẫo de } 10 \mathrm{mg} / \mathrm{L} \\
\text { de tetraciclina }\end{array}$ & $1,37 \times 10^{8}$ & $S C$ & $\mathrm{sc}$ & $\mathrm{SC}$ \\
\hline
\end{tabular}

Os resultados obtidos confirmaram a ação inibitória da concentração de $10 \mathrm{mg} / \mathrm{L}$ de tetraciclina sobre os lactobacilos testados, mostrando sua eficiência e viabilidade na contagem seletiva e isolada de Pediococcus pentosaceus em ágar MRS para produtos cárneos fermentados contendo esses microrganismos. Nesse sentido, a contagem dos lactobacilos probióticos é expressa como a diferença entre a contagem total de bactérias lácticas em ágar MRS sem adição de tetraciclina e a contagem de Pediococcus em ágar MRS adicionado de $10 \mathrm{mg} / \mathrm{L}$ de tetraciclina.

Testou-se também a eficiência da tetraciclina em menor concentração no meio de cultura. Na concentração de $5 \mathrm{mg} / \mathrm{L}$ de ágar verificou-se crescimento das cepas puras de L. casei, L. paracasei e L. rhamnosus, juntamente com o crescimento de Pediococcus pentosaceus. Contudo, as colônias dos Lactobacillus mostraram diâmetro muito reduzido quando comparado ao seu diâmetro em ágar MRS puro. Além disso, as colônias de Pediococcus pentosaceus apresentaram coloração branca, superfície brilhante e suave com diâmetro aproximado de $2 \mathrm{~mm}$.

\section{CONCLUSÃO}

As espécies de Lactobacillus testadas apresentaram crescimento satisfatório na presença dos sais de cura, demonstrando potencial para sua utilização no desenvolvimento de produtos cárneos fermentados com ação probiótica.

A adição de tetraciclina ao ágar MRS na concentração de $10 \mathrm{mg} / \mathrm{L}$ permitiu o crescimento seletivo de Pediococcus pentosaceus, possibilitando a contagem isolada dos pediococos utilizados como cultura starter em 
derivados cárneos fermentados e dos lactobacilos probióticos adicionados aos produtos cárneos.

\begin{abstract}
CHARACTERISTICS OF PROBIOTIC CULTURES FOR THE USE IN FERMENTED MEAT PRODUCTS - SENSIBILITY TO CURING SALTS AND ANTIBIOTIC USE FOR THE SELECTIVE ENUMERATION

The objective of this study was to evaluate the resistance of probiotic species of Lactobacillus in the presence of curing salts and to test their sensibility in the presence of antibiotics for the development of a selective culture media. The probiotic cultures, Lactobacillus casei, Lactobacillus paracasei spp paracasei and Lactobacillus casei spp rhamnosus, were plated in MRS agar with concentration of 0 to $3 \%$ of sodium chloride and 0 to $200 \mathrm{ppm}$ of sodium nitrite. The inhibitory effect of $3 \%$ sodium chloride and 200 ppm sodium nitrite in simultaneous use was evaluated for the probiotic strains. The sensibility of the starter culture, Pediococcus pentosaceus and the probiotic cultures in the presence of antibiotic was carried out using 20 different antibiotic discs by the disc-diffusion technique. The growth of the probiotic cultures wasn't affected at different concentrations of sodium chloride, and even to concentrations of $200 \mathrm{ppm}$ of sodium nitrate. Resistance was verified by simultaneous use of sodium chloride and nitrate. Among the tested antibiotics, tetracycline showed a satisfactory inhibition effect for the probiotic strains, since the growth of starter Pediococcus pentosaceus was not affected. The probiotics showed satisfactory growth in the presence of curing salts, demonstrating potential use in fermented meat products with probiotic action.
\end{abstract}

KEY-WORDS: PROBIOTICS; FERMENTED MEAT PRODUCTS; CURING SALTS.

\title{
REFERÊNCIAS
}

1 ANDERSEN, L. Fermented dry sausages produced with the admixture of probiotic cultures. In: INTERNATIONAL COMMITMENT OF MEAT SCIENCE AND TECHNOLOGY, 44., Barcelona, 1998. Anais... Barcelona: Institut de Recerca i Tecnologia Agroalimentaries, 1998. p. 826-827.

2 ARIHARA, K.; ITOH, M. UV-induced Lactobacillus gasseri mutants resisting sodium choride and sodium nitrite for meat fermentation. International Journal of Food Microbiology, v. 56, p. 227-230, 2000.

3 CANHOS, A. L.; DIAS, E. L. Tecnologia de carne bovina e produtos derivados. Campinas: ITAL, 1985. 440 p.

4 CARR, F. J.; CHILL, D.; MAIDA, N. The lactic acid bacteria: a literature survey. Critical Reviews in Microbiology, v. 28, p. 281-370, 2002.

$5 \quad$ ERKKILÄ, S; SUIHKO, M. L.; EEROLA, S.; PETÄJÄ, E.; MATTILASANDHOLM, T. Dry sausage fermented by Lactobacillus rhamnosus 
strains. International Journal of Food Microbiology, v. 64, p. 205210, 2001.

6 HAMMES, W. P.; HERTEL, C. New developments in meat starter cultures. Meat Science, v. 49, p. 125-138, 1998.

7 LABORCLIN. Tabela de sensibilidade dos discos de antibióticos. 3. ed. Pinhais, 2003. Ficha para interpretação dos resultados (monodiscos e polidiscos de antibióticos Laborclin).

8 LÜCKE, F. K. Utilization of microbes to process and preserve meat. Meat Science, v. 56, p. 105-115, 2000.

9 PAPAMANOLI, E.; TZANETAKIS, N.; LITOPOULOU-TZANETAKI, E.; KOTZEKIDOU, P. Characterization of lactic acid bacteria isolated from a Greek dry-fermented sausage in respect of their technological and probiotic properties. Meat Science, v. 65, p. 859-867, 2003.

10 SAMESHIMA, T.; MAGOME, C.; TAKESHITA, K.; ARIHARA, K.; ITOH, M.; KONDO, Y. Effect of intestinal Lactobacillus starter cultures on the behaviour of Staphylococcus aureus in fermented sausage. International Journal of Food Microbiology, v. 41, p. 1-7, 1998.

11 SILVA, N.; JUNQUEIRA, V. C. A.; SILVEIRA, N. F. A. Manual de métodos de análise microbiológica de alimentos. 2. ed. rev. ampl. São Paulo: Livraria Varela, 2001. $317 \mathrm{p}$.

12 THARMARAJ, N.; SHAH, N. P. Selective enumeration of Lactobacillus delbrueckii ssp. Bulgaricus, Streptococcus thermophilus, Lactobacillus acidophilus, Bifidobacteria, Lactobacillus casei, Lactobacillus rhamnosus, and Propionibacteria. Journal of Dairy Science, v. 86, p. 2288-2296, 2003.

13 TTYÖPPÖNEN, S.; PETÄJÄ, E.; MATTILA-SANDHOLM, T. Bioprotectives and probiotics for dry sausages. International Journal of Food Microbiology, v. 83, p. 233-244, 2003. 